\title{
Elementos da crítica de Adorno a Kant
}

\author{
Ricardo Musse \\ Universidade de São Paulo \\ rmusse@usp.br
}

resumo Procura-se, por meio da análise imanente da segunda parte do livro Dialética negativa, destacar os elementos centrais da posição de Adorno frente a Kant. Torna-se assim possível estabelecer a singularidade de Adorno perante as críticas empreendidas pelo idealismo alemão, por Nietzsche, pela psicanálise e pela própria tradição marxista na qual ele se insere. Sua proposta consiste em submeter a filosofia transcendental a uma segunda reflexão que desemboque no materialismo, constituindo um "duplo giro copernicano".

palavras-chave Adorno; Kant; idealismo; materialismo

A teoria materialista postulada por Adorno se apresenta como uma espécie de prosseguimento da filosofia kantiana. Para tanto, ele não tem como deixar de proceder a um rigoroso ajuste de contas com a filosofia transcendental. A segunda parte do livro Dialética negativa contém uma crítica imanente do idealismo kantiano, desenvolvida a partir do ponto que Adorno considera como o mais indeterminado na obra de Kant, o material da afecção empírica.

Preocupado em contestar o primado da subjetividade, Adorno mostra-se atento sobretudo ao momento não-conceitual, ao rudimento metalógico da lógica formal, ao resquício de facticidade não eliminável por meio dos desdobramentos do raciocínio, em suma, volta-se para aquilo que não é idêntico ao pensamento. Mas sua rejeição do núcleo ativo do princípio da identidade só se configura plenamente quando aborda a relação entre o conceito e o não-conceitual.

Recebido em 16 de outubro de 2006. Aceito em dezembro de 2006.

doispontos, Curitiba, São Carlos, vol. 4, n. 1, p. 201-215, abril, 2007 
Segundo Adorno, a posição ôntica do material da afecção sensorial na Crítica da razão pura não lhe garante nenhuma prioridade em relação a qualquer outro ente real. Contingente tanto em relação ao transcendental, como em relação ao sujeito, ele aponta, em seu nexo necessário com o sujeito transcendental, para as antinomias da filosofia kantiana:

caso a forma, o sujeito transcendental, precisasse rigorosamente da sensação para funcionar, ou seja, para julgar de modo válido, então ele estaria fixado, quase ontologicamente, não apenas à apercepção pura mas também ao seu pólo oposto, à sua matéria [...] As sensações, a matéria kantiana, sem as quais as formas não seriam sequer representáveis e que são, portanto, por sua vez, condições de possibilidade do conhecimento, tem o caráter do efêmero. (ADORNO, 1982, p. 141)

A determinação do momento ôntico do sujeito transcendental coloca em xeque a ilusão kantiana de uma constituição inteiramente subjetiva, aflorando a contradição que lhe é inerente.

Ao desdobrar a crítica ao idealismo, Adorno procura evitar uma recaída na contra-ontologia, o paradoxo da constituição de uma ontologia do nãoontológico. A sensação, o algo, o não-idêntico ao pensamento, interessa-lhe não como substituto do conceito, como um primeiro, constitutivo, mas enquanto mera abstração, como indício do "teor coisal" < Sachhaltige>, que ele considera o verdadeiro objeto do pensamento filosófico:

O menor resíduo ôntico nos conceitos aos quais a filosofia regular se esfrega em vão obriga-a a introduzir de modo refletido o próprio seraí, em vez de se contentar com o seu simples conceito e de aí se pretender ao abrigo do que ele significa. O pensamento filosófico não tem por conteúdo o que resta após a supressão do espaço e do tempo, tampouco considerações gerais acerca do espaço-temporal. Ele se cristaliza no particular, naquilo que é determinado no espaço e no tempo (ADORNO, 1982, p. 142).

A objeção de Adorno à filosofia kantiana remete, portanto, à suposição de que Kant teria desdenhado o teor coisal. Esse descaso, segundo ele, engendra uma dialética que afeta todo o sistema. A determinação da coisa como algo caótico se transmite até o sujeito, que é reduzido a um ponto 
abstrato da razão, ou melhor, à não-contradição lógica, o que não deixa de contagiar o próprio objeto de conhecimento.

Desse modo, a determinação do objeto como um diverso desprovido de qualidades contamina a própria noção de sujeito transcendental:

como em verdade, sujeito e objeto não estão, como no esquema kantiano, fixados um face ao outro, mas se penetram reciprocamente, a degradação kantiana da coisa em um abstrato caótico afeta também a força que o deve formar. [...] No trabalho categorial, o sujeito se esgota e empobrece; para poder determinar, articular aquilo que está à sua frente de maneira a que se torne objeto no sentido kantiano, é necessário que o sujeito, por amor à validade objetiva de suas determinações, se dilua à mera universalidade, amputando de si mesmo não menos que do objeto de conhecimento, afim de que este último, conforme ao programa, seja reduzido ao seu conceito. (ADORNO, 1982, p. 142-3)

Nessa interpretação, a afirmação da unidade sintética da apercepção como um primeiro coloca em cena, a contragosto, o seu correlato apropriado, a coisa concebida como algo inferior e heterogêneo. Como fracassa a tentativa de descartá-la, prima philosophie e "dualismo" caminham lado a lado. Pressupostos como pólos indeterminados, genéricos e insuficientemente mediados, sujeito e objeto engendram o dualismo kantiano, desmontando a afirmação inicial de que a determinação seria puramente subjetiva. Afirma-se assim o caráter vão da pretensa soberania do sujeito, abrindo caminho para uma dialética negativa que retenha e transforme os conceitos e as categorias da filosofia transcendental.

$\mathrm{Na}$ estratégia de Adorno, a configuração da antinomia kantiana é apenas o primeiro passo. Em seguida, ele radicaliza as posições antagônicas, contrapõe conceitos contraditórios, procurando trazer à superfície um movimento inconsciente. ${ }^{1}$ Orientada pelo projeto de conduzir uma autocrítica do conceito, a dialética negativa propõe-se a reformular radicalmente as categorias kantianas, produzindo uma alteração de tal monta que, ao afetar cada uma delas em particular, transmuta toda a constelação. ${ }^{2}$

No entanto, a dialética entre o conceito e o ente não se configura como uma mera relação espacial que se restrinja a constatar a exterioridade e situar o ente como estranho à articulação dos juízos. Tampouco se 
trata de alcançar ou mesmo mirar um alvo colocado no interior dos fenômenos, mas sim de detectar essa relação no próprio cerne do conceitual. Afinal, a mediação não é capaz de suprimir totalmente o imediato, uma vez que mesmo aquilo que se afigura inapreensível pela mediação não desaparece nela.

Em Adorno, a "imediaticidade" não se configura como uma modalidade de conhecimento; consiste antes em algo dotado de existência objetiva. Não há como buscá-la fora da mediação, uma vez que nada pode ser pensado sem o pensamento. Cabe então procurá-la no próprio núcleo da ordem conceitual. Dessa forma, o ente, a sensação, o não-idêntico não se configuram como contrapontos abstratos da essência ou da categoria, mas se apresentam no interior do próprio pensamento.

Desse modo, Adorno pressupõe a tese kantiana do "giro copernicano", isto é, a afirmação de que o conhecimento não parte de um objeto externo, mas o constitui subjetivamente. Somente após reter esse momento subjetivo, o ponto de vista da mediação, da intentio obiqua, e em conseqüência dele, é que ele sustenta que "aquilo que mediatiza os fatos não é tanto o mecanismo subjetivo que os preforma e os apreende, mas a objetividade heterônoma ao sujeito, situada atrás daquilo que ele pode experimentar" (ADORNO, 1982, p. 172). ${ }^{3}$

O materialismo proposto por Adorno não afirma dogmaticamente o ente como um primeiro, mas o reencontra no núcleo do conceitual. Nesse sentido, seu projeto de reformulação qualitativa dos conceitos e categorias kantianas pode ser descrito como desdobramentos efetivos de um projetado "duplo giro copernicano". ${ }^{4}$

Pode-se dizer que a teoria que Adorno desenvolve em sua Dialética negativa, enfatizando a "primazia do objeto", passa ao largo das tentativas idealistas do pós-kantismo de determinar a relação da coisa em si com o sujeito transcendental. Embora Adorno reconheça que esta deva possuir um mínimo de determinações negativas, pelo simples fato de, por definição, diferenciar-se daquilo que pode ser subsumido pela predicação categorial, julga essa dualidade imprecisa e indeterminada: "Só é legítimo falar acerca da primazia do objeto quando esta primazia é determinável de alguma maneira frente ao sujeito, entendido este no sentido mais lato, quando é mais que a coisa em si kantiana, enquanto causa desconhecida do fenômeno" (ADORNO, 1980, p. 158).

doispontos, Curitiba, São Carlos, vol. 4, n. 1, p. 201-215, abril, 2007 
Compreendida em sentido forte como uma determinação contundente, a "primazia do objeto" altera qualitativamente o ponto de vista próprio à consciência reificada, que se conforma normalmente ao subjetivismo. Não se esquiva tampouco de contestar o fundamento filosófico dessa visada, a doutrina kantiana do realismo empírico segundo a qual a objetividade da empiria é garantida de antemão, restando apenas proporcionar os critérios formais de sua validez.

A desmontagem, desenvolvida pela moderna ciência da natureza, do aparato categorial, das determinações precisas estabelecida por Kant em sua tábua de categorias, coloca em questão o subjetivismo aí implícito. As determinações categoriais que são o guia na busca kantiana de objetividade surgem, em sua contingência, como meramente subjetivas.

A teoria da precedência do objeto visa, na direção inversa, determinar o aparato categorial por meio daquilo que, no esquema kantiano, deveria ser determinado por ele. Adorno reafirma assim a possibilidade de apreender o caráter condicionado do condicionante. Por sua vez reduzida, dessa forma, à condição de mero subjetivismo, a contingência das categorias kantianas desmente tanto o mito de um espírito criador quanto o antropocentrismo inerente ao idealismo.

O procedimento adotado por Adorno é a decantação da história sedimentada no conceito de sujeito transcendental. ${ }^{5}$ Trata-se de mostrar como a teoria kantiana da subjetividade, ao consumar a transmutação do sujeito em objeto, confirma a teoria marxista da reificação. ${ }^{6}$

A dominação universal do valor de troca sobre os homens, que nega a priori aos sujeitos o direito de serem sujeitos, rebaixa a própria subjetividade a simples objeto, relega à não-verdade este princípio de universalidade que afirma instaurar a predominância do sujeito

(ADORNO, 1982, p. 180).

Adorno procura modificar a orientação dos procedimentos tradicionais de "conceptualização", tomando o cuidado de não desconsiderar o sujeito empírico, o que lhe permite remeter os conceitos a uma dialética que não prescinde da não-identidade. $O$ seu objetivo é inverter a tendência dominante na reflexão epistemológica que sempre reduz a objetividade ao sujeito.

doispontos, Curitiba, São Carlos, vol. 4, n. 1, p. 201-215, abril, 2007 
Para tanto, convém encaminhar a reflexão ao exame dos pressupostos da concepção de sujeito instaurada pela intentio obliqua (e predominante na teoria do conhecimento): a doutrina que compreende o sujeito transcendental como uma subjetividade constitutiva do mundo objetivo. Trata-se de desviar o foco para a questão da constituição. A tentativa kantiana de estabelecer, no capítulo acerca dos paralogismos psicológicos, uma diferença entre o sujeito transcendental e o sujeito empírico organiza-se como um círculo que atesta que o sujeito transcendental foi abstraído dos indivíduos, dos singulares "viventes". Seguindo essa direção, Adorno se propõe a estabelecer, noutros moldes e com outros propósitos, a diferença "fundamental, constitutiva e hierárquica" entre o sujeito transcendental e o sujeito empírico.

É claro que ele não ignora a distinção fundamental da filosofia kantiana entre o momento empírico da subjetividade e o transcendental. No entanto, recusa a separação e a abstração que, segundo ele, inverte totalmente a ordem da constituição. Afinal, insiste Adorno, "sem nenhuma relação a uma consciência empírica, à do eu vivente, não haveria a consciência transcendental, puramente espiritual" (ADORNO, 1982, p. 186).

Adorno reapresenta a distinção kantiana entre a esfera empírica e a transcendental combinando elementos de crítica à sociedade e ao conhecimento, a partir de uma questão considerada filosoficamente como secundária: a pergunta pela efetividade do sujeito transcendental. ${ }^{7}$ Segundo esse critério, o sujeito transcendental é mais determinante para a vida real dos homens e da sociedade do que os sujeitos empíricos do qual foi abstraído: "Tal como está forçado a agir e para o que foi em si modelado, o homem particular vivente, encarnação do homo oeconomicus, é antes o sujeito transcendental do que o indivíduo vivente" (ADORNO, 1980, p. 155). Por seu papel na "deformação" dos indivíduos, o sujeito transcendental passa a ser considerado (enquanto expressão filosoficamente transfigurada da sociedade de troca) como "constitutivo".

Inverte-se, assim, a questão filosófica da constituição. A tese da anterioridade da sociedade sobre os indivíduos é ampliada: a sociedade não apenas precede, ela também "constitui" os sujeitos empíricos. ${ }^{8}$ Essa objetividade heterônoma, segundo Adorno "recusa o ć́rculo primeiro da experiência subjetiva, ela o precede". Afinal, face à consciência individual, o sujeito transcendental

doispontos, Curitiba, São Carlos, vol. 4, n. 1, p. 201-215, abril, 2007 
representa não apenas o mais abstrato, mas também em virtude de sua potência formante, o mais efetivo. Além do círculo mágico da filosofia da identidade, o sujeito transcendental é passível de ser decifrado como a sociedade inconsciente de si mesma (ADORNO, 1982, p. 178-9).

Moldado pelo ente $<$ Seienden $>$, o conceito de subjetividade deixa perceber, quando se torna alvo da reflexão epistemológica, o seu caráter de "objetividade" cuja ausência parecia distingui-lo do factual. Na realidade, a essencialidade do sujeito pressupõe a faticidade, inclusive como sua condição de possibilidade:

Não somente o eu puro é mediatizado onticamente pelo eu empírico, que transparece inequivocamente como modelo da primeira versão da dedução dos conceitos puros do entendimento, mas também o é o próprio princípio transcendental no qual a filosofia crê possuir aquilo que para ela é primeiro face ao ente. (ADORNO, 1982, p. 178)

Recusando-se a se reconhecer como dependente do ente, o sujeito se arvora à condição de soberano. Assim, apenas nega, ironicamente, o seu lócus próprio:

Nos mecanismos subjetivos de mediação se perpetuam aqueles da objetividade, aos quais está atrelado cada sujeito, mesmo o transcendental. $O$ fato de que os dados, por sua exigência, sejam apercebidos de certo modo e não de outro, é assegurado pela ordem pré-subjetiva que, por sua vez, constitui essencialmente a subjetividade constituinte da teoria do conhecimento. (ADORNO, 1982, p. 172)

Adorno vai além e contesta o princípio fundamental da subjetividade kantiana, na acusação de que seu modelo de sujeito está moldado pela faticidade e de ser assim desprovido (apesar da definição de seu uso transcendental) daquilo que se definiu como sendo sua característica-mor: a espontaneidade.

Instala-se, assim, ao mesmo tempo a "primazia do objeto" e a anterioridade do pensamento e da linguagem em relação aos indivíduos empíricos. ${ }^{9}$ Conserva-se, de um modo sui generis, o resultado obtido pelo idealismo; apenas, porém, para negá-lo sob o lema de um "duplo giro copernicano". 
Como se mostrou acima, a interpretação que Adorno desdobra acerca do sujeito kantiano parece retomar três momentos distintos da crítica ao idealismo: (a) a vertente psicanalítica - que atribui ao sujeito transcendental uma super-estimação narcisística do eu, uma hybris de sua autonomia; (b) a tradição marxista - que o interpreta como um caso extremo de ideologia; (c) a crítica nietzscheana - que o acusa de não ser mais que um elemento de auto-conservação da espécie. Podemos acrescentar um quarto momento a essa interpretação, a preocupação de Adorno em mostrar como o sujeito transcendental expressa também, de alguma forma, o princípio de dominação da natureza. ${ }^{10}$

No entanto, seu projeto não reside propriamente em confirmar, complementar ou combinar as diversas vertentes críticas que a posterioridade endereçou à filosofia kantiana. Propõe-se, sobretudo, a alertar para um aspecto freqüentemente esquecido e, no entanto, decisivo: nenhuma dessas críticas invalida, por si só, a capacidade cognoscente do transcendental. Essa capacidade, por sua vez, conforme atesta a crítica da "teoria do conhecimento", deriva de uma universalidade que não é apenas ilusória, mas também real.

De acordo com o propósito adorniano de contestar a ilusão de uma subjetividade constitutiva, ${ }^{11}$ não se trata de rejeitar o sujeito transcendental, o idealismo ou mesmo a filosofia mas, eis aí o cerne do projeto de um "duplo giro copernicano", ir além e detectar o seu solo real: "O processo de abstração transfigurado pela filosofia e atribuído só ao sujeito cognoscente desenrola-se na sociedade de troca real" (ADORNO, 1982, p. 180). ${ }^{12}$

Desvenda-se assim a contradição inerente à constituição que pretende fazer de tal sujeito um universal filosófico, pela via desmonte do mecanismo filosófico idealista que constrói a unidade da consciência tornando ubíquo o paradigma da consciência individual. Cabe não esquecer que se tal modelo é adequado para exprimir a objetividade, isto é, a possibilidade de constituição dos objetos da experiência, é porque a própria consciência individual já é "o reflexo conceitual da reunião total e sem falhas dos atos de produção na sociedade pelos quais primeiro constitui a objetividade das mercadorias, o seu 'caráter objetivo"' (ADORNO, 1982, p. 181). ${ }^{13}$ 
Adorno não concebe a obra de Kant como uma mera transfiguração filosófica do subjetivismo. O principal mérito da filosofia transcendental assenta-se, ao contrário, em seu esforço de busca da objetividade, ainda que procure situá-la nas "condições constitutivas da subjetividade". Ao superar o dilema entre razão e experiência, Kant recoloca a questão da objetividade sob uma nova forma na qual os momentos do subjetivo e do objetivo não são simplesmente opostos, mas se encontram mediados um pelo outro.

A tarefa do "duplo giro", portanto, consiste em mostrar que as formas do pensamento, os "constituintes" - que na perspectiva idealista apresentam-se como a condição de possibilidade da objetividade - só conservam sua porção de objetividade porque esta, na verdade, em vez de ser posta pelo sujeito, deriva do objeto: "agora é a subjetividade que é mediatizada antes que a objetividade e uma tal mediação precisa mais urgentemente de análise que a mediação tradicional" (ADORNO, 1982, p. 173).

Não se trata, porém, apenas de ressaltar que o fundamento da objetividade kantiana encontra-se em outro lugar. Impõe-se submeter as formas constituintes a uma transformação qualitativa, a uma metamorfose na qual o aparato do apriorismo idealista deixe de ser o elemento constitutivo do conhecimento, conservando interesse apenas como "objeto de conhecimento".

$\mathrm{Na}$ verdade, se o conjunto idealista composto por essas formas lógicas deixa de ser pensado como algo que o sujeito impõe ao objeto (isto é, como uma racionalidade à qual o mundo deveria conformar-se) e passa, por sua vez, a indicar o momento de passividade (um conjunto formal segundo o qual os indivíduos são coagidos a adequar-se), a tarefa do conhecimento exige que se prescinda de tal aparato lógico ou, pelo menos, do apriorismo. $\mathrm{O}$ ato de conhecer deixa assim de ser concebido como a descoberta ou a invenção de novas formas lógicas, de estruturas apriorísticas. A análise kantiana da faculdade de conhecer, no entanto, não deve ser descartada sem mais. Uma vez que tal análise foi desdobrada conforme uma intenção objetiva, torna-se possível, pelo prosseguimento da reflexão, isto é, por meio de uma metacrítica, desencadear um processo de revisão dos conceitos que permita contestar não apenas a soberania do sujeito, mas também o próprio idealismo, indicando e possibilitando a "passagem ao materialismo".

doispontos, Curitiba, São Carlos, vol. 4, n. 1, p. 201-215, abril, 2007 
Adorno adverte que o "dado", em sua pobreza e cegueira, não pode ser confundido com a objetividade. Ele importa sobretudo como obstáculo à tentativa idealista de dominação subjetiva do objeto. Desse modo, situando o objeto como algo mais que pura faticidade (e esta como não-eliminável), ele desprende-se tanto da concepção abstrata de objeto, própria do empirismo, como da pretensão kantiana de catalogar os dados sensíveis.

Pode-se dizer, portanto, que a noção de objeto desdobrada por Adorno, atenta à necessidade de solapar a primazia do sujeito (e de impedir a redução da multiplicidade a uma simples unidade) exige a crítica seja da tentativa de inventariar subjetivamente os dados externos, seja de seu correlato, a ficção da existência de um factual desprovido de determinações e até mesmo da conjunção de ambos, isto é, da possibilidade de uma adição de faticidade e conceito.

Diferentemente de certas vertentes, Adorno não considera a doutrina do "realismo empírico" como germe de uma possível metamorfose materialista da obra de Kant. Para ele, se é possível detectar a presença de um "germe materialista" na filosofia transcendental, este deve ser buscado no dualismo kantiano ou então na doutrina da coisa em si. Cabe observar que Adorno abandona, na linhagem do idealismo alemão, a doutrina kantiana do realismo empírico, embora valorize, em outra direção, a sensação. ${ }^{14}$ Isso decorre de sua intenção paradoxal de reconstruir o materialismo a partir do lema especulativo de "primazia do objeto", descartando a afirmação dogmática de uma realidade anterior à consciência. Seu materialismo é conseqüência de uma efetiva auto-reflexão e, como tal, apresenta-se não como ponto de partida, mas como resultado final.

Nesse sentido, justifica-se a necessidade de conservar, ao menos como ponto de partida e momento inicial, o giro copernicano. Adorno utilizao como arma contra o empirismo, mas também contra um materialismo vulgar que só aparentemente, ou melhor, apenas exteriormente refuta os pressupostos da virada kantiana:

O sujeito enquanto momento é inapagável. Uma vez eliminado o momento subjetivo, o objeto se desfaria como as emoções fugidias e os instantes da vida subjetiva. Objeto, mesmo enfraquecido, tampouco é sem o sujeito. Se o sujeito faltasse como momento no próprio objeto, a objetividade desse último tornar-se-ia nonsense. (ADORNO, 1980, p. 166) 
O objeto inicial da reflexão adorniana não é algo intemporal, mas aquilo que foi sedimentado historicamente como objeto. Não se trata, portanto, de montar mais uma construção lógica. Mas cabe observar que esse objeto tampouco é algo meramente empírico, pois se insere no âmbito do conceito. Possui então esse duplo caráter, inimaginável para a filosofia transcendental: é, ao mesmo tempo, conceitual e temporal. Daí o descarte que ele promove da tentativa kantiano de apreender o mundo empírico (a experiência dada) por meio das formas da intuição sensível. É necessário suplantar esse modelo por algo mais abrangente - pela experiência histórica.

O “duplo giro copernicano", proposto por Adorno, não apenas aponta para a viragem ao materialismo, como ainda permite a revisão dos conceitos de sujeito, objeto e de sua mútua relação por meio de uma dialética assentada na não-identidade, denominada, por ele, de "negativa".

$\mathrm{Na}$ esteira de Hegel que considerou a obra de Kant como uma forma de filosofia da subjetividade, Adorno atribui à filosofia transcendental a pecha de "subjetivismo". ${ }^{15}$ Sua censura, porém, não se assenta na defesa de uma filosofia do absoluto ou mesmo no impulso de apreender a idéia infinita; o que ele contesta em Kant é, sobretudo, a afirmação do primado do sujeito. Ao descrever o subjetivismo kantiano, isto é, o fato de que nada se sabe a não ser por meio do sujeito cognoscente, Adorno reconhece um momento de verdade inerente ao "fenomenalismo". Essa aparência necessária., no entanto teria conduzido Kant a conceber o sujeito como constitutivo, a colocar o aparato categorial como modelo da subjetividade, a considerar o objeto como posto pelo sujeito.

Fica claro, portanto, que o conceito de "subjetivismo" não possui em Adorno o mesmo significado que lhe é atribuído por Hegel. No caso desse último, o termo designa a ausência de mediação pelo objeto, uma dialética incompleta. Já em Adorno indica a tirania do sujeito, o esquecimento de que o ele também é objeto, a "ilusão constitutiva". ${ }^{16}$ Embora rejeite o sujeito transcendental, Adorno conserva algo da subjetividade kantiana: "Mas como o primado do objeto necessita da reflexão sobre o 
sujeito e da reflexão subjetiva, a subjetividade, diferentemente do materialismo primitivo, que propriamente não admite dialética, torna-se um momento retido" (ADORNO, 1980, p. 158-9).

No esforço de suplantar a objetividade kantiana, Adorno evita negar de forma peremptória a teoria desenvolvida na Crítica da razão pura. Contenta-se em indicar suas insuficiências. Propõe-se a situar a objetividade transcendental no quadro de uma constelação conceitual ordenada em função de uma reflexão sobre a própria teoria do conhecimento: "Dar-se conta do fato de o pensar ser mediado pela objetividade não nega o pensar e as leis objetivas pelas quais é pensar" (ADORNO, 1982, p. 182).

Adorno concorda com a interpretação e o diagnóstico de Hegel quando este acusa o subjetivismo kantiano de acomodar suas determinações categoriais ao realismo empírico, fornecendo critérios formais para justificá-lo. Porém, novamente segue um desvio: não reclama de Kant a radicalização idealista exigida por Hegel, ${ }^{17}$ mas confronta a pretensão da filosofia transcendental de ter deduzido as categorias do entendimento em sua integralidade com as novas categorias desentranhadas pelas modernas ciências da natureza, que colocam em xeque o subjetivismo kantiano.

A objetividade posta por Kant, segundo Adorno, fracassa porque, por um lado, o seu apriorismo consegue na união sintética uma homogeneidade que só se explica pela realização subjetiva da síntese, mas, por outro lado, para que esta síntese não seja mera tautologia do sujeito deve conter pelo menos em parte algo da objetividade. A objetividade, por conseguinte, não podendo ser deduzida inteiramente pela subjetividade, passa a depender do conteúdo, da matéria do conhecimento, que se apresenta como algo dado, indissolúvel, dissociado do sujeito.

$\mathrm{Da}$ fonte desse fracasso Adorno extrai a lição de que "Kant não teria podido reclamar as formas subjetivas como condição da objetividade se não lhes houvesse tacitamente concedido uma objetividade tomada de empréstimo daquela à qual contrapõe o sujeito" (ADORNO, 1980, p. 165). Afinal, a afirmação subjetiva de algo dotado de "objetividade" é derivada, pressupõe um objeto. A própria noção de objetividade, no acomodar-se do pensamento ao que lhe é externo (mesmo quanto não o possui e o considere apenas como produzido) subjaz implícita a "primazia do objeto". 18

doispontos, Curitiba, São Carlos, vol. 4, n. 1, p. 201-215, abril, 2007 
Desse modo, o lema hegeliano de entregar-se, sem reservas, ao objeto, à coisa mesma, torna-se verdadeiro não porque o objeto se torna sujeito no decorrer do processo, como queria Hegel, mas exatamente porque o objeto não é seu produto, o que torna ainda mais necessária a exigência de dirigir seu olhar para ele. Isso, paradoxalmente, implica uma insistência ainda maior na reflexão subjetiva, pensada, entretanto, não mais como constitutiva, mas como palco da experiência espiritual, num exercício totalmente distinto do automatismo que Kant assimilou à experiência.

1 Segundo Adorno, "a concepção kantiana permitia ainda dicotomias como as de forma e conteúdo, sujeito e objeto, sem que a mediação mútua destes pares de opostos a desconcertasse; ela não notava ainda a sua essência dialética, a contradição como implicada em seu sentido" (ADORNO, 1982, p.140).

2 Pensando a articulação conceitual como um campo de forças, Adorno afirma: "Lá onde uma categoria se altera - [...] pela dialética negativa - altera-se a constelação de todas as categorias e com isto, por sua vez, cada uma delas" (ADORNO, 1982, p. 169).

3 Tal conclusão pode ser apreendida da observação da própria dedução transcendental das categorias do entendimento: "Aquilo que na dedução kantiana das categorias permanece ao final, segundo sua própria confissão, como contingente, como dado: que a razão dispõe destas categorias e não de outras, isto decorre daquilo que as categorias, segundo Kant, pretendem primeiro instaurar" (ADORNO, 1982, p.173).

4 As expressões, recorrentes na obra de Adorno, "duplo giro copernicano", "passagem ao materialismo" e "primazia do objeto" designam momentos de uma mesma constelação teórica. Para uma descrição dos diferentes campos de força instaurados por cada uma dessas configurações confira MUSSE, 2003.

5 Adorno prioriza o exame da estrutura da subjetividade kantiana, uma vez que a objetividade na filosofia transcendental é constituída a partir desta: "no sentido de Kant não é possível nenhum mundo, nenhum constitutum, sem as condições subjetivas da razão, do constituens" (ADORNO, 1966, p. 21).

6 “O giro copernicano de Kant acerta exatamente a objetificação do sujeito, a realidade da reificação” (ADORNO, 1980, p.163).

${ }^{7}$ Adorno acusa os principais sucessores de Kant - em especial, Fichte, Hegel e Schopenhauer - de fugirem dessa questão recorrendo ao "tropos" aristotélico que postula, como fundamento primeiro, uma condição ou origem para aquilo que é primeiro para a consciência: o sujeito empírico (cf. ADORNO, 1982, p. 154).

8 Ao reproduzir e manter as condições da vida, ou seja, enquanto condição de possibilidade da existência dos indivíduos, a sociedade deixa as suas marcas na linguagem e no pensamento que, assim, também precedem o indivíduo (cf. ADORNO, 1982, p.155-6).

doispontos, Curitiba, São Carlos, vol. 4, n. 1, p. 201-215, abril, 2007 
${ }^{9}$ A preponderância da objetividade nos sujeitos não só os impede de tornarem-se propriamente sujeitos, como também dificulta o conhecimento objetivo (cf. ADORNO, 1982, p.172-4).

10 Cabe notar que a análise do sujeito transcendental também desemboca em uma reflexão acerca do impasse do projeto iluminista. Afinal, "se a dominação da natureza foi condição e etapa da desmitologização, esta última tem agora que abranger aquela dominação, caso não queira tornar-se vítima do mito" (ADORNO, 1982, p. 181). Sobre isso cf. também ADORNO e HORKHEIMER, 1985, p. 81-112.

11 Adorno é enfático acerca da necessidade de se libertar da ilusão de uma subjetividade constitutiva: "a enfase filosófica no poder constitutivo do momento subjetivo nos impede o acesso à verdade” (ADORNO, 1982, p.181-2).

12 A determinação do sujeito transcendental como necessário, associada à sua funcionalidade e à universalidade, "tem a sua realidade na dominação que se afirma e se eterniza pelo princípio de equivalência” (ADORNO, 1982, p.180).

13 O princípio do eu imita aquilo que nega. O caráter sólido, estável, impenetrável do eu é adquirido pela mimesis da impenetrabilidade do mundo exterior. O papel constitutivo do sujeito representa, portanto, uma "auto-elevação desesperada, uma reação à experiência de sua impotência que entrava a auto-reflexão; a consciência absoluta é inconsciente" (ADORNO, 1982, p.181).

14 Adorno valoriza a sensação como forma de, entre outras coisas, refutar a noção póskantiana de "espírito".

15 Uma breve exposição da crítica que Hegel endereça à filosofia de Kant pode ser encontrada em HEGEL, 1986, p. 112-147.

16 Adorno não exime Hegel da acusação de subjetivismo, que, de modo geral, associa com a ideologia: "Quanto mais os homens singulares são realmente rebaixados a funções da totalidade social por sua vinculação com o sistema, tanto mais o homem em geral, como princípio dotado dos atributos da criatividade e da dominação absoluta, é consoladoramente elevado pelo espírito" (ADORNO, 1980, p.154).

17 Adorno critica Hegel por tentar substituir o subjetivismo pela positividade (cf. ADORNO, 1982, p.161).

18 A funcionalidade, a atividade pura do sujeito transcendental que se cumpre nas performances dos sujeitos singulares e, ao mesmo tempo, os ultrapassa demonstra que o sujeito transcendental é modelado não apenas pelo eu empírico, mas expressa o trabalho social, o trabalho intelectual hipostasiado (cf.ADORNO, 1982, p. 179).

\section{Referências bibliográficas}

ADORNO, Theodor. 1966. Drei Studien zu Hegel. Frankfurt am Main: Suhrkamp. 
ADORNO, Theodor. 1982. Negative Dialektik. Frankfurt am Main: Suhrkamp.

ADORNO, Theodor. 1980. Stichworte. Frankfurt am Main: Suhrkamp.

ADORNO, Theodor e HORKHEIMER, Max .1985. Dialética do esclarecimento. Rio de Janeiro: Jorge Zahar Editor.

KANT, Immanuel. 1985. Crítica da razão pura. Lisboa: Calouste Gulbenkian.

HEGEL, Georg Wilhelm Friedrich (1986). Enzyklopädie der philosophischen Wissenschaften, vol. I. Frankfurt am Main: Suhrkamp.

MUSSE, Ricardo. 2003. Passagem ao materialismo. Lua Nova, nº. 60, p. 97-116. São Paulo: Cedec. 
